\title{
Erratum to: Can a Short Course of Prophylactic Low-Dose Proton Pump Inhibitor Therapy Prevent Stomal Ulceration after Laparoscopic Roux-en-Y Gastric Bypass?
}

Mathieu André D'Hondt • Hans Pottel •

Dirk Devriendt • Frank Van Rooy •

Franky Vansteenkiste

Published online: 9 February 2010

(C) Springer Science+Business Media, LLC 2010

Erratum to: OBES SURG

DOI 10.1007/s11695-009-0062-x

The first author's middle name was mistakenly captured as part of his surname in the original article. The correct abbreviation is D'Hondt, M. A.

The online version of the original article can be found under at http:// dx.doi.org/10.1007/s11695-009-0062-x.

M. A. D’Hondt $(\bowtie) \cdot$ D. Devriendt $\cdot$ F. Van Rooy •

F. Vansteenkiste

Groeninge Hospital,

Houtmarkt 33, 8500 Kortrijk, Belgium

e-mail: mathieudhondt2000@yahoo.com

H. Pottel

Interdisciplinary Research Center,

Katholieke Universiteit Leuven,

Kortrijk, Belgium 